\title{
Molecular characterization of vernalization loci VRN1 in wild and cultivated wheats
}

\author{
Kseniya A Golovnina ${ }^{1 *}$, Elena Ya Kondratenko², Alexander G Blinov ${ }^{1}$, Nikolay P Goncharov ${ }^{2}$
}

\begin{abstract}
Background: Variability of the VRN1 promoter region of the unique collection of spring polyploid and wild diploid wheat species together with diploid goatgrasses (donor of B and D genomes of polyploid wheats) were investigated. Accessions of wild diploid (T. boeoticum, T. urartu) and tetraploid (T. araraticum, T. timopheevii) species were studied for the first time.

Results: Sequence analysis indicated great variability in the region from -62 to -221 nucleotide positions of the VRN1 promoter region. Different indels were found within this region in spring wheats. It was shown that VRN1 promoter region of $\mathrm{B}$ and $\mathrm{G}$ genome can also contain damages such as the insertion of the transposable element. Some transcription factor recognition sites including hybrid C/G-box for TaFDL2 protein known as the VRN1 gene upregulator were predicted inside the variable region. It was shown that deletions leading to promoter damage occurred in diploid and polyploid species independently. DNA transposon insertions first occurred in polyploid species. At the same time, the duplication of the promoter region was observed in A genomes of polyploid species.

Conclusions: We can conclude that supposed molecular mechanism of the VRN1 gene activating in cultivated diploid wheat species T. monococcum is common also for wild T. boeoticum and was inherited by T. monococcum. The spring polyploids are not related in their origin to spring diploids. The spring T. urartu and goatgrass accessions have another mechanism of flowering activation that is not connected with indels in VRN1 promoter region. All obtained data may be useful for detailed insight into origin of spring wheat forms in evolution and domestication process.
\end{abstract}

\section{Background}

Some plants of middle latitudes require vernalization treatment (a long exposure to low temperatures) to induce their flowering. This adaptation appeared to protect flower from destruction by cold temperature during winter. Besides being an important trait for adaptation, the requirement of vernalization is also of a great agronomical importance. In crops such as common wheat (Triticum aestivum L.), a vernalization requirement distinguishes winter varieties from spring ones. Spring growth habit is a potential advantage in cold climates, with short vegetation season and cold winter, for agriculture which main task is to achieve rich harvest. In continental middle latitude areas (from $40^{\circ}$ to $60^{\circ} \mathrm{N}$ latitude) the field is occupied for two vegetation seasons by

\footnotetext{
* Correspondence: ksu@bionet.nsc.ru

'Laboratory of Molecular-Genetic Systems, Institute of Cytology and Genetics, Novosibirsk 90, Russian Federation

Full list of author information is available at the end of the article
}

winter forms and only for one season - by spring ones. So spring forms allow obtaining two harvests instead of one of winter growth habit forms, which, moreover, do not overwinter every year. Due to this reason, the processes underlining vernalization and genes responsible for this agronomical feature have been of interest for many years [1]. Increasing knowledge about the molecular genetics of growth habit (spring vs. winter) would contribute to a better understanding of the evaluation of adaptation in crops. This data would promote wheat breeding for specific environments.

In recent years, researchers made some breakthroughs in understanding of the molecular mechanisms of vernalization in wheat, a plant of prime agronomic importance. Sequences of three vernalization genes VRN1, $V R N 2, V R N 3$ responsible for spring-winter growth habit have been determine [2-5].

The predicted model shows that the VRN1 gene is dominant for spring growth habit and it is the main 
initiating factor of the flowering regulatory cascade that is upregulated by VRN3 (similar to Arabidopsis FLOWERING LOCUS T, FT) [6]. Whereas VRN2 gene is dominant for winter growth habit, it has been suggested that mediated protein [7]. In a complementary study, it was shown that nucleotide polymorphisms or insertionsdeletions on A and D copies of the wheat FT gene can also explain variations for heading date [8].

Investigation of the photoperiod influence on the regulation of vernalization genes showed that down-regulation of the VRN2 by switching from LD (long day) to SD (short day) treatment has no effect on the regulation of VRN1 until plants are transferred again to LD [9]. These data suggest the existence of one more VRN1 repressor.

It has been demonstrated that functional difference between the dominant $V r n 1$ and recessive $v r n 1$ alleles in cultivated diploid T. monococcum L. (genome $\mathrm{A}^{\mathrm{b}} \mathrm{A}^{\mathrm{b}}$ ) is due to deletions in the promoter region (near CArGbox) [3]. Vrn-A1 alleles of the common wheat (genome $\mathrm{BBA}^{\mathrm{u}} \mathrm{A}^{\mathrm{u}} \mathrm{DD}$ ) and the tetraploid T. turgidum L. (genome $\mathrm{BBA}^{\mathrm{u}} \mathrm{A}^{\mathrm{u}}$ ) have also nucleotide deletions as well as insertions of mobile elements in VRN1 promoter and large deletions inside the first intron $[10,11]$. At the same time, the dominant $V r n-B 1$ and $V r n-D 1$ genes are caused only by large deletions in the first intron [11]. It is more likely that VRN1 promoter and the first intron regions contain the regulatory sites for different protein interactions. CArG-boxes are generally recognized by MADS-box genes and considered as the critical regulatory site for the response of VRN1 to SD. Recently, this hypothesis was refuted [12]. However, damages in either intron or promoter sites are sufficient to accelerate flowering under LD $[10,11]$. These data suggest the existence of interactions between these two mechanisms in the regulation of the VRN1 gene expression.

Most of the wild Triticeae Dum. species have a winter growth habit, suggesting that the recessive vrn1 allele is the ancestral feature. In contrast, the majority of cultivated polyploid wheats are spring species [13]. Only T. aestivum has the similar number of spring and winter forms http://www.vir.nw.ru and adaptability of landraces differed depending on their growth habit and VRN genotype [14]. Their growth habit is due to at least one dominant Vrn1 allele. This allele could be either inherited from ancestral diploids or could result from selection of independent mutations that appeared during the adaptation to various growing condition after domestication. Moreover, genetic and molecular experiments show that there are multiple alleles of dominant Vrn1, and their manifestation in vernalization response is also different $[15,16]$. It means that some mechanisms exist, for which evolutionary background is unknown. In the present study, molecular variability of wheat VRN1 promoter region was analyzed. In order to get a more detailed insight into complicated molecular basis of spring $v s$. winter growth habit and associated vernalization genes variability, we studied wild and cultivated wheats together with their close relatives Aegilops L. In total, 27 accessions of four diploid species (T. urartu Thum. ex Gandil., T. boeoticum Boiss., T. monococcum and T. sinskajae A. Filat. et. Kurk.) and 17 accessions of 7 polyploid species belonging to three known sections (Dicoccoides Flaksb., Triticum, Timopheevii A. Filat. et Dorof.) were investigated. Seven accessions of goatgrasses belonging to 2 species (Aegilops squarossa L., Aegilops speltoides Tausch), which participated in the hybridization events in polyploidy wheat evolution, were also studied. Among all 51 investigated accessions, eight have winter growth habit, and the remaining - spring growth habit. The number of genes responsible for spring $v s$. winter growth habit was estimated in the genetic experiments for ten spring accessions.

\section{Results}

\section{Genetic analysis of growth habit (spring vs. winter)}

For the molecular characterization, it was important to study accessions that possess monogenic control of spring growth habit. Genetic experiments were carried out to demonstrate genetic control of growth habit in some spring wheat and goatgrass species. The obtained data are given in Tables 1 and 2 .

It was established that spring growth habit of most of examined species was controlled by a single dominant gene. In the Table 1 the segregation ratio 3 to 1 is reliable while the value of Pierson chi-square test for the segregation ratio 15 to 1 is higher than the value of significance 3.84 . Three investigated tetraploid species were crossed with near-isogenic test lines, which were characterized with specific dominant $V r n-A 1$ (i: BS1E), $V r n-B 1$ (i: BS2E) alleles. The design of near-isogenic lines is described in Methods section. In crosses with $T$. dicoccum cv. Black Winter Emmer (BWE), which has recessive $v r n-A 1$ and $v r n-B 1$ alleles, it was shown that spring growth habit of these species was controlled monogenic, because the segregation ratio 3 to 1 in $\mathrm{F}_{2}$ generation is reliable. For T. turanicum (K-15993) monogenic control was shown indirectly from the next two crosses, where the digenic segregation (15 to 1 ) was obtained for all three species. It means that dominant allele responsible to spring growth habit is not allelic to $\mathrm{Vrn}-\mathrm{Al}$ and $\mathrm{Vrn}$ $B 1$ alleles of the tested lines.

In tetraploid wheat species, the dominant gene of the accessions K-15993 and K-16156 was temporarily designated as $V r n-T$ and their genotypes were specified as $v r n-A 1 v r n-A 1$ vrn-B1vrn-B1 VrnTVrnT. It is an unknown allele, which is nonallelic to $V r n-A 1$ and to $V r n-B 1$. The number and allelity of dominant genes 
Table $1 F_{2}$ segregation for growth habit and tests of conformity to one and two gene ratios in crosses of $T$. urartu (u), T. boeoticum (b), T. monococcum (m), T. sinskajae (s) and Ae. squarrosa (ae)

\begin{tabular}{|c|c|c|c|c|}
\hline \multirow[t]{2}{*}{ Cross combination } & \multicolumn{2}{|c|}{ Segregation into winter vs. spring forms in the $F_{2}$ generation } & \multicolumn{2}{|c|}{$\chi^{2}$ value for ratio* } \\
\hline & spring & winter & 3:1 & $15: 1$ \\
\hline $\mathrm{mKT} 3-5 \times \mathrm{mPI} 306547$ & 113 & 38 & 0,00 & 92,21 \\
\hline $\mathrm{mPI306547 \times b|G116198}$ & 14 & 4 & 0,07 & 7,84 \\
\hline bK25811 × blG45296 & 96 & 30 & 0,10 & 66,31 \\
\hline $\mathrm{bK}-20741 \times \mathrm{mPI} 306547$ & 53 & 27 & 3,27 & 103,25 \\
\hline $\mathrm{blG} 116198 \times \mathrm{mPI} 35526$ & 57 & 13 & 1,54 & 18,14 \\
\hline sK-48993 × mPI13962 & 146 & 55 & 0,60 & 152,92 \\
\hline aeK-992 $\times$ aeK-608 & 37 & 0 & - & - \\
\hline aeK-865 × aeKU2009 & 117 & 0 & - & - \\
\hline aeKU2009 × aeKT120-16 & 197 & 50 & 2,98 & 82,54 \\
\hline
\end{tabular}

* - values for significance of $P=0.05$ is 3.84 and $P=0.01$ is 5.99; spring accessions are underlined

VRN1 in T. timopheevii (Zhuk) Zhuk. was not determined because all accessions of this species had only spring growth habit [13]. The generalized information concerning genetic control of growth habit is represented in Table 3.

\section{Allelic variability at the VRN1 promoter region of diploid species \\ Variability at the primer annealing site}

In the present work, 27 diploid wheat accessions of four known species (T. urartu: winter - K-33869, PI538736; spring - PI428297, PI428197, IG44829, IG45298; T. monococcum: winter - PI94743; spring - K-20400, K18105, Mute KT3-5, K-20970, PI306540; T. boeoticum: winter - G1777, K-25811; spring - IG116198, K-14384, PI428217, IG116196, PI427328, K-20741, IG45296, K40117, K-40118, KU8136, KU8120, KU8059; T. sinskajae: spring - K-48993) and 7 goatgrass accessions of two species (Ae. speltoides: winter - Ae46593, spring Ae46566; Ae. squarrosa: spring - K-992, K-865, K-608, K-864, KU2009) were studied (see Material section and Table 3). Initial PCR screening was provided with primer pair AP1_ProDel_F1, AP1_ProDel_R1 (Table 4). The PCR product of the expected size of $152 \mathrm{bp}$ has been obtained in the majority of the studied wheat accessions and in one goatgrass species, Ae. speltoides (Fig. 1). No PCR products have been found in Ae. squarrosa accessions. Out of 27 wheat accessions, ten showed PCR products of the lower size, which can be explained by deletions in the promoter region.

The heterogeneity of diploid genomes and their sequence variability was observed previously $[17,18]$. All available VRN1 promoter sequences belonging to different wheat genomes (A, B, D) were extracted from GenBank and aligned together with primer sequences. There were a 17 bp deletion in $\mathrm{D}$ genome near the region complementary to the reverse primer (AP1_ProDel_R1), and a duplicated fragment (CCTCAC) near this region in A genome (Fig. 2). Therefore, a new primer pair was developed (AP1_2F/ AP1_2R) for amplification of D genome. To check for possible minor deviations connected with spring growth habit, all fragments obtained in PCR using both primer pairs were directly sequenced. The resulting sequences were submitted to GenBank: GQ451714-GQ451749.

The presence of the specific deletions in spring wild and cultivated accessions

Among 22 investigated spring diploid wheats, 9 (T. monococcum: K-18105, T. boeoticum: K-40117, K40118, PI427328, K-20741, IG45296, KU8136, KU8120, KU8059) had 20 bp or 34 bp deletions in VRN1 promoter

Table 2 Calculation of number of VRN genes in tetraploid wheat species

\begin{tabular}{|c|c|c|c|c|}
\hline \multirow[t]{2}{*}{ Species, accessions } & \multicolumn{3}{|c|}{ Segregation into spring vs. winter forms in the $F_{2}$ generation } & \multirow[t]{2}{*}{ Genotype (Haploid) } \\
\hline & BWE (vrn-A1) & BS1E (Vrn-A1) & BS2E (Vrn-B1) & \\
\hline T. durum cv. Kristall (Vrn-D4) & $50: 16^{1)}$ & $116: 13^{2)}$ & $122: 6^{21}$ & Vrn-D4 \\
\hline T. turgidum K-16156 & $187: 57^{1)}$ & $60: 5^{2)}$ & $28: 3^{2)}$ & $v r n-A 1 v r n-B 1 V r n-T$ \\
\hline T. turanicum K-15993 & - & $157: 10^{2)}$ & $69: 7^{2)}$ & $v r n-A 1 v r n-B 1 V r n-T$ \\
\hline
\end{tabular}


Table 3

\begin{tabular}{|c|c|c|c|c|c|}
\hline Genus, section, genome, species & $\begin{array}{l}\text { Accession-voucher, } \\
\text { cultivars }\end{array}$ & $\begin{array}{l}\text { Gr. } \\
\text { habit }\end{array}$ & $\begin{array}{l}\text { Genotype or number of } \\
\text { dominant genes* }\end{array}$ & $\begin{array}{l}\text { VRN1 } \\
\text { allele** }\end{array}$ & GenBank Ac.N. \\
\hline \multicolumn{6}{|l|}{$\begin{array}{l}\text { Triticum L. } \\
\text { section Urartu Dorof. et A.Filat. } \\
A^{u} A^{u} \\
\text { T. urartu Thum. ex Gandil. }\end{array}$} \\
\hline & K-33869 & W & & $v r n-A 1$ & GQ451714 \\
\hline & PI538736 & W & & vrn-A1 & GQ451724 \\
\hline & PI428297 & $S$ & unknown & $v r n-A 1$ & GQ451721 \\
\hline & PI428197 & $\mathrm{S}$ & unknown & vrn-A1 & GQ451723 \\
\hline & IG44829 & $\mathrm{S}$ & unknown & vrn-Alu & GQ451737 \\
\hline & IG45298 & $S$ & unknown & $v r n-A 1$ & GQ451736 \\
\hline
\end{tabular}

section Monococcon Dum.

$A^{b} A^{b}$

T. monococcum L.

\begin{tabular}{|c|c|c|c|c|c|}
\hline & PI94743 & W & & $v r n-A 1$ & GQ451733 \\
\hline & K-20400 & $S$ & mono[44] & $v r n-A 1$ & GQ451715 \\
\hline & K-18105 & S & unknown & Vrn-Alg & GQ451717 \\
\hline & Mute KT3-5 & $S$ & mono (Table1) & $v r n-A 1$ & GQ451725 \\
\hline & K-20970 & $\mathrm{S}$ & unknown & $v r n-A 1$ & GQ451730 \\
\hline & PI306540 & $\mathrm{S}$ & unknown & vrn-A1 & GQ451732 \\
\hline \multicolumn{6}{|c|}{ T. boeoticum Boiss. } \\
\hline & G1777 & W & & $v r n-A 1$ & GQ451718 \\
\hline & $\mathrm{K}-25811$ & W & & $v r n-A 1$ & GQ451728 \\
\hline & IG116198 & $S$ & mono (Table1) & Vrn-Alh & GQ451727 \\
\hline & K-14384 & $\mathrm{S}$ & unknown & $v r n-A 1$ & GQ451716 \\
\hline & PI428217 & $\mathrm{S}$ & unknown & vrn-Al & GQ451719 \\
\hline & IG116196 & $S$ & mono (Table1) & vrn-A1 & GQ451720 \\
\hline & PI427328 & $\mathrm{S}$ & unknown & Vrn-Alh & GQ451722 \\
\hline & K-20741 & $\mathrm{S}$ & mono (Table1) & Vrn-Alh & GQ451734 \\
\hline & IG45296 & $S$ & mono (Table1) & Vrn-Alh & GQ451735 \\
\hline & K-40117 & $\mathrm{S}$ & unknown & Vrn-A1g & GQ451738 \\
\hline & $\mathrm{K}-40118$ & $S$ & unknown & Vrn-Alh & GQ451739 \\
\hline & KU8136 & $S$ & unknown & Vrn-Alh & GQ451743 \\
\hline & KU8120 & $\mathrm{S}$ & unknown & Vrn-Alh & GQ451744 \\
\hline & KU8059 & $S$ & unknown & Vrn-Alh & GQ451745 \\
\hline \multicolumn{6}{|c|}{ T. sinskajae A. Filat. et Kurk. } \\
\hline & K-48993 & $S$ & [45] mono (Table1) & $v r n-A 1$ & GQ451729 \\
\hline \multicolumn{6}{|c|}{$\begin{array}{l}\text { section Dicoccoides Flaksb. } \\
B B A^{u} A^{u} \\
\text { T. turgidum L. }\end{array}$} \\
\hline & K-16156 & $S$ & Vrn-T (Table 2) & $\begin{array}{l}\text { vrn-A1u } \\
v r n-B 1\end{array}$ & GQ451819-GQ451820 \\
\hline \multicolumn{6}{|l|}{ T. durum Desf. } \\
\hline & spring line cv.Kristall & $S$ & Vrn-D4 (Table 2) & $\begin{array}{l}\text { Vrn-Ale } \\
\text { vrn-B1 }\end{array}$ & GQ451821-GQ451822 \\
\hline \multicolumn{6}{|c|}{ T. dicoccum (Schrank) Schuebl. } \\
\hline & i: BS1E & $S$ & Vrn-A1 [36] & $\begin{array}{l}\text { Vrn-Ala } \\
v r n-B 1^{3}\end{array}$ & GQ451756-GQ451759 \\
\hline & $\mathrm{i}: \mathrm{BS} 2 \mathrm{E}$ & $S$ & Vrn-B1 [36] & $\begin{array}{l}\text { Vrn-A1b } \\
\text { vrn-B1 }\end{array}$ & GQ451760-GQ451761 \\
\hline
\end{tabular}


Table 3 (Continued)

\begin{tabular}{|c|c|c|c|c|c|}
\hline T. turanicum Jakubz. & & & & & \\
\hline & K-15993 & S & Vrn-T (Table 2) & $\begin{array}{l}\text { Vrn-A1f } \\
v r n-A 1 u^{2} \\
v r n-B 1\end{array}$ & GQ451815-GQ451818 \\
\hline & K-11597 & S & unknown & 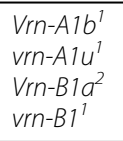 & GQ451768-GQ451772 \\
\hline \multicolumn{6}{|l|}{$\begin{array}{l}\text { section Triticum } \\
B B A^{u} A^{u} D D \\
\text { T. aestivum L. }\end{array}$} \\
\hline & $\begin{array}{l}\text { cv. Mironovskaya } \\
\text { yubileinaya }\end{array}$ & W & & $\begin{array}{l}\text { vrn-A1u } \\
\text { vrn-B1 } \\
\text { vrn-D1 }\end{array}$ & GQ451781-GQ451783 \\
\hline & cv. Mironovskaya 808 & W & & $\begin{array}{l}\text { vrn-A1u } \\
\text { vrn-B1 } \\
v r n-D 1^{2}\end{array}$ & GQ451784-GQ451787 \\
\hline & $\begin{array}{l}\text { nulli5B-tetra5 D } \\
\text { Chinese Spring }\end{array}$ & S & Vrn-D1 (4 dose) [46] & 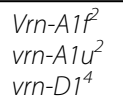 & GQ451773-GQ451780 \\
\hline & cv. Pyrothrix 28 & $\mathrm{~S}$ & Vrn-A1b, VrnB1 [15] & $\begin{array}{l}v r n-A 1 u^{3} \\
v r n-B 1 \\
v r n-D 1^{2}\end{array}$ & GQ451788-GQ451793 \\
\hline & cv. Jupateko & S & Vrn1 (weak) [47] & $\begin{array}{l}\text { Vrn-A1f } \\
\text { Vrn-A1a } \\
\text { vrn-A1u } \\
\text { vrn-B1 } \\
\text { vrn-D1 }\end{array}$ & GQ451794-GQ451798 \\
\hline & $\begin{array}{l}\text { s: Saratovskaya/ } \\
\text { Vietnamskaya } \\
\text { 5R(5A) }\end{array}$ & S & unknown & $\begin{array}{l}\text { Vrn-A1b3 } \\
\text { vrn-B1 } \\
\text { vrn-D1 }\end{array}$ & $\begin{array}{l}\text { GQ451799-GQ451803, } \\
\text { GQ451814 }\end{array}$ \\
\hline & $\begin{array}{l}\text { cv. Mironovskaya } \\
\text { yarovaya }\end{array}$ & S & $\operatorname{Vrn} 1[48]$ & 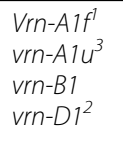 & GQ451804-GQ451809 \\
\hline & cv. Osijek & S & Vrn-A1b [47] & $\begin{array}{l}\text { vrn-A1u, } \\
\text { vrn-B1 } \\
\text { vrn-D1 }\end{array}$ & GQ451810-GQ451813 \\
\hline \multicolumn{6}{|c|}{$\begin{array}{l}\text { section Timopheevii A. Filat. et Dorof. } \\
\text { GGA } A^{b} \\
\text { T. araraticum Jakubz. }\end{array}$} \\
\hline & K-28244 & S & unknown & $\begin{array}{l}\text { Vrn-Alf } \\
\text { Vrn-G }\end{array}$ & GQ451762-GQ451767 \\
\hline \multicolumn{6}{|c|}{ T. timopheevii (Zhuk) Zhuk. } \\
\hline & K-38555 & S & unknown & $\begin{array}{l}\text { Vrn-A1f } \\
\text { Vrn-A1u' } \\
\text { Vrn-G1a }\end{array}$ & GQ451750-GQ451755 \\
\hline \multicolumn{6}{|l|}{ Tetraploid line } \\
\hline & PI428276 & S & unknown & $\begin{array}{l}\text { Vrn-A1g } \\
\text { Vrn-Alf } \\
\text { Vrn-Alu } \\
V r n-A 1^{1}\end{array}$ & GQ482969-GQ482975 \\
\hline
\end{tabular}

Aegilops L.

section Sitopsis (Jaub. \& Spach) Zhuk. SS Ae speltoides Tausch

$\begin{array}{llll}\text { Ae46593 W } & \text { Vrn-S } & \text { GQ451726 }\end{array}$


Table 3 (Continued)

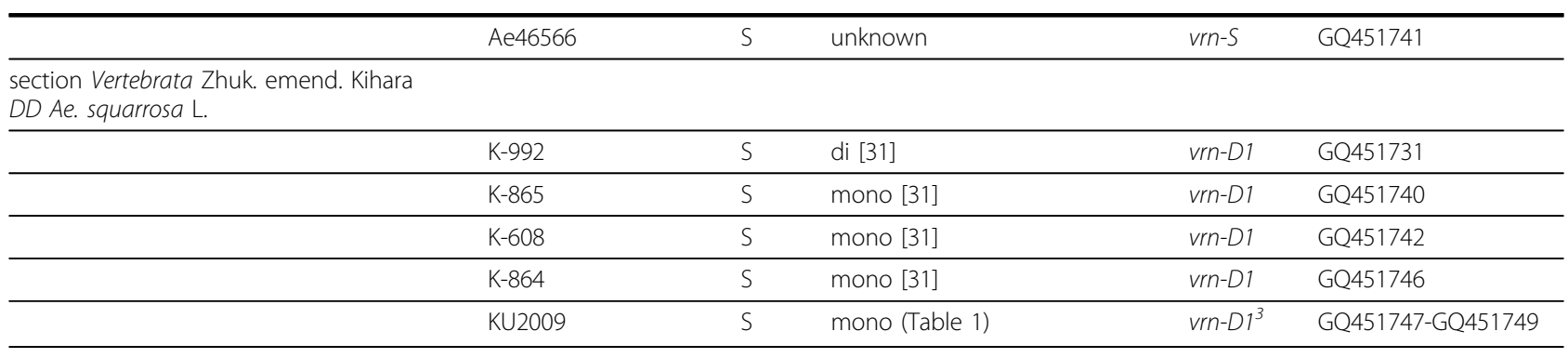

region comparing with winter ones (Table 3, Fig. 2). Both deletions covered the specific area of MADS-box, and were previously described as associated with spring growth habit in the diploid cultivated wheat T. monococcum $[3,4]$. Spring $T$. boeoticum accessions were not screened previously as well as $T$. urartu. Investigation of the VRN1 promoter mutations in both species may provide important information about mechanisms involved in the origin of the spring forms in these wild natural species. Among four spring T. urartu accessions, none had specific deletions within the VRN1 promoter region compared to winter forms. However, one accession was almost identical to the A genome sequences of the polyploid wheats (Fig. 2). This recessive allele was named $v r n-A 1 u$ and was not found in all analyzed T. boeoticum and T. monococcum sequences (Table 3 ).

The closest relatives of Triticum L. species are Aegilops L. species, which also have spring and winter forms. In order to address the question whether flowering initialization in spring goatgrasses has common characters with that of diploid wheats, we obtained VRN1 promoter regions from six spring and one winter Aegilops accessions. There were some nucleotide substitutions differentiating goatgrasses from wheats (see additional file 1). No significant changes, which could distinguish spring and winter accessions, have been found. All investigated promoter sequences of the Ae. squarrosa accessions contained the specific D genome 17 bp deletion (Fig. 2) and some D genome specific nucleotide substitutions.

\section{Allelic variation at the VRN1 promoter region in polyploid wheats \\ Tetraploid wheat species}

VRN1 promoter regions from G genomes of spring $T$. timopheevii (K-38555) and T. araraticum Jakubz. (K-28244) were amplified using primer specific for B genome. We analyzed also a tetraploid line determined by karyological analysis (PI428276), which was found in an accession of $T$. urartu from Lebanon. Sequencing showed a close relatedness of the obtained $\mathrm{G}$ genome to the corresponding $B$ genome (see additional file 2). The most interesting was the presence in T. timopheevii G genome and two clones of T. turanicum Jakubz. B genome of several identical substitutions and large insertions in -100 position upstream from the start codon. The insertions were 196 bp long in G genome and 127 bp in B genome (Fig. 3). We named these VRN1 promoter variants $V r n-G 1 a$ and $V r n-B 1 a$. These insertions were similar to a 222 bp foldback element (GenBank: AY616458) observed in Vrn-A1a allele and named "Spring" (Fig. 4). However, the site of insertion was different. It was not in the place of the CArG box (CCTCGTTTTGG) and was flanked by another host direct duplication (HDD - CTCCGCCCC) (Fig. 3).

More detailed analysis of the mobile elements which were found in Vrn-A1, Vrn-B1 and Vrn-G1 promoter regions of tetra- and hexaploid wheat species showed the presence of the terminal inverted repeats (TIR) and predicted open reading frames between both repeats (Fig. 4). The observed transposon element, which is $222 \mathrm{bp}$ in length with $29 \mathrm{bp}$ TIR, could belong to the superfamily Tc1/Mariner.

The VRN1promoter regions from A genomes of spring tetraploids also contain different promoter damages and share some variability. In addition, a $50 \mathrm{bp}$ deletion was found in the region -112 and -62 nucleotide from start codon. This deletion was located in the same region where the foldback element insertion occurred in the G genome (Fig. 3). This VRN1 promoter allele was called Vrn-A1f. Species of the section Dicoccoides, T. turanicum (K-11597) and T. dicoccum (Schrank) Schuebl. (line BS2E) also had a common 20 bp deletion in the region -156 -136 upstream from the start codon. This deletion included the repetitive region and was observed previously in $V r n-A 1 b$ and $V r n-A 1 d$ alleles of spring tetraploid T. durum Desf. and T. dicoccoides correspondingly [10]. We observed also a $54 \mathrm{bp}$ deletion in A genome of T. durum (spring line of cv. Kristall (Vrn-D4), Odessa) that was similar to Vrn-A1e alleles of $T$. dicoccum. VRN1 promoter from A genome of $T$. dicoccum (near-isogenic line BS1E - Black Spring $V r n 1$ Emmer) displayed identity with $V r n-A 1 a$ allele observed previously in $T$. aestivum near-isogenic line Triple Dirk D (TDD) and contained the insertion of a foldback element. 
Table 4 Primer pairs used in the study

\begin{tabular}{clc}
\hline Name & Sequence & Reference \\
\hline AP1_ProDel_F1 & 5'ACAGCGGCTATGCTCCAG3' & {$[3]$} \\
AP1_ProDel_R1 & 5'AATCAGGTGGTTGGGTGAGG3' & {$[3]$} \\
\hline AP1_2F & 5'CTGTGGTGTGTGTTTGTGGCGAGAG3' & Present study \\
AP1_2R & 5'ACCCTACGCCCCTACCCTCCAACAC3' & \\
\hline VRN1-AF & 5'GAAAGGAAAATTCTGCTCG3' & {$[10]$} \\
VRN1-BF & 5'CAGTACCCCTGCTACCAGTG3' & {$[10]$} \\
VRN-DF & 5'CGACCCGGGCGGCACGAGTG3' & {$[10]$} \\
VRN1-1NT1R & 5'TGCACCTTCCC(C/G)CGCCCCAT3' & {$[10]$} \\
\hline
\end{tabular}

\section{Hexaploid wheat species}

Promoter sequences of vrn-A1, vrn-B1 and vrn-D1 alleles from two winter cultivars (Mironovskaya yubileinaya, Mironovskaya 808) and A, B and D genome sequences of spring mute Mironovskaya yarovaya were determined. The spring mute was found in cultivar Mironovskaya 808. VRN1 promoter fragments of winter cultivars and B, D genome of spring Mironovskaya yarovaya contained a common for certain genomes variability observed in recessive alleles of winter wheat near-isogenic line Triple Dirk C (TDC) [10]. After cloning and sequencing of A genome fragment of spring sample, clones with and without specific deletions were observed. The observed deletions included 8 bp del in $-128-120$ region and $50 \mathrm{bp}$ del in $-112-62$ region that were common for the $V r n-A 1 f$ allele described above in tetraploid species (Table 3, Fig. 3).

Three T. aestivum cultivars Pyrothrix 28, Osijek and Jupateko with "weak" Vrn1 alleles (low phenotype

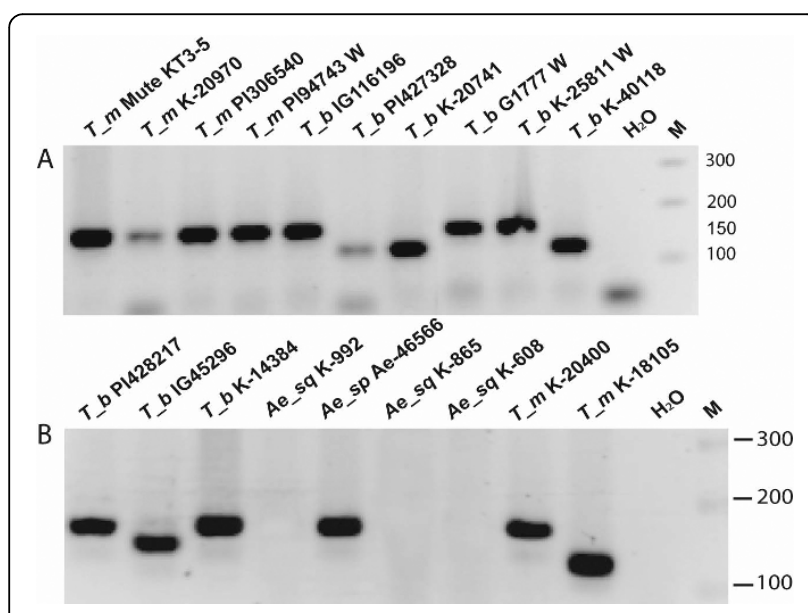

Figure 1 PCR amplification of VRN1 promoter region with primers AP1_ProDel_F1/AP1_ProDel_R1. A. Diploid wheat accessions. T_b - T. boeoticum, T_m - T. monococcum, Ae_sp - Ae. speltoides, Ae_sq - Ae. squarrosa. T_b PI-427328, K-20741, K-40118 have 20 bp deletion. $W$ - winter growth habit. B. Spring diploid Triticum and Aegilops accessions. T_b IG-45296 has 20 bp deletion, T_m K-18105 has 34 bp deletion. M - Marker-Bioline HyperLader IV. manifestation allele) [15] were also included in the research. No differences from recessive alleles were found in VRN1 promoter sequences from A, B and D genomes of spring cvs. Osijek and Pyrothrix 28; as well as from B and D genomes of spring cv. Jupateko. After amplification of the VRN1 promoter region from A genome of the cv. Jupateko, two PCR products were visualized on electrophoresis. Sequencing of two larger PCR products revealed the presence of the foldback element insertions that was common for VrnA1-a allele [10]. A $222 \mathrm{bp}$ foldback element insertion differed moderately from those previously described. The site of insertion and flanking direct repeats (TTAAAAACC) were similar for both elements. However, analysis of the foldback element of spring cv. Jupateko indicated an absence of direct repeats inside (Fig. 4). These direct repeats were the sites of deletions in the duplicated promoter sequences of $V r n-A 1 a$ allele. Therefore, we detected only one variant of the promoter with mobile element insertion in this species. The smaller PCR products in cv. Jupateko had most common character with $V r n-A 1 f$ allele observed in K-38555 T. timopheevii. Thus, two different $V r n-A 1$ alleles were detected. Both alleles could be the cause of spring growth habit.

We also found promoter damages in the A genomes of two other investigated intrageneric T. aestivum: substitution line Saratovskaya/Vietnamskaya 5R(5A) and line nulli5B-tetra5D Chinese Spring. The investigated promoter regions contained $V r n-A 1 b$ and $V r n-A 1 f$ alleles correspondingly (Table 3 ). Both alleles could be a reason of spring growth habit and likely inherited from tetraploid species during cultivation and breeding programs.

\section{Variability of different clones inside A genome}

Investigation of $\mathrm{A}$ genome sequences revealed at least two different variants of VRN1 promoter in some cloned samples according to the presence of indels. At the same time all cloned $B$ and $D$ genome sequences were identical in the presence or absence of indels. To exclude any doubt in affiliation with a specific genome, we provided the phylogenetic analysis, which allowed the correlation of each sequence into the genome (see additional file 3). Each of three accessions of Diccoccoides section (T. turanicum K-11597, K-15993; $T$. dicoccum line BS1E) had two different variants of the promoter in A genome. One of them was intact as in winter $v r n-A 1$ allele, and another had a deletion or insertion of the transposon (Fig. 5). VRN1 promoters of the remaining three examined species $(T$. dicoccum line BS2E, T. durum line Kristall (Vrn-D4), T. turgidum K-16156) were sequenced directly without cloning and contain only one variant of sequence judging from the absence of superpositions in the chromatograms. 


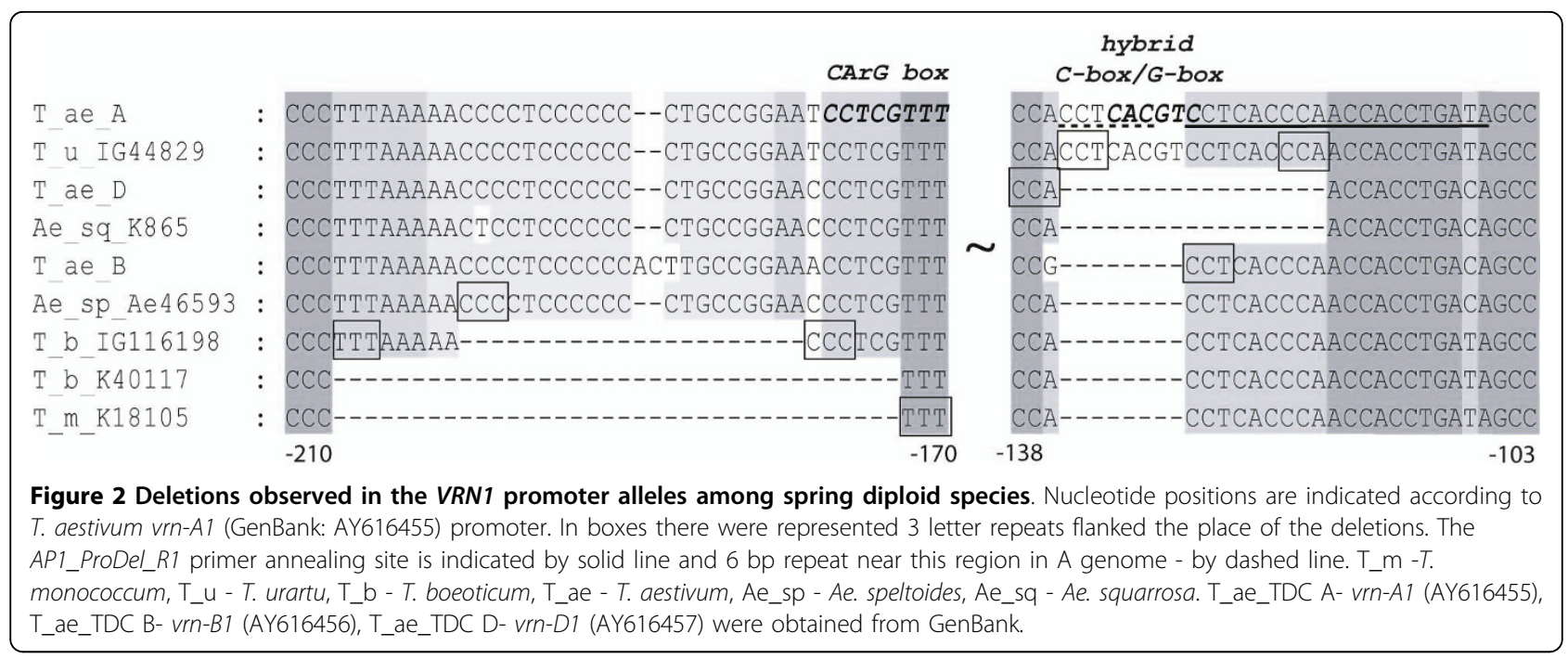

In section Timopheevii four clones of T. araraticum (K-28244) were similar if indels are taken into consideration. T. timopheevii (K-38555) had four clones similar to those of $T$. araraticum (K-28244) containing Vrn-Alf allele and one clone with intact $v r n-A 1$ allele. Absence of the previously determined A genome specific $8 \mathrm{bp}$ insertion in the region -120-128 were observed in some clones of the tetraploid species. Only A genome had variability at this region while $B, G$ and $D$ genomes as well as genomes of the examined goatgrasses were conservative and had deletions in this place. All obtained $V r n-A 1 f$ allele had no 8 bp insertion.

Seven clones of VRN1 promoter region from A genome were sequenced in tetraploid line discovered in $T$.

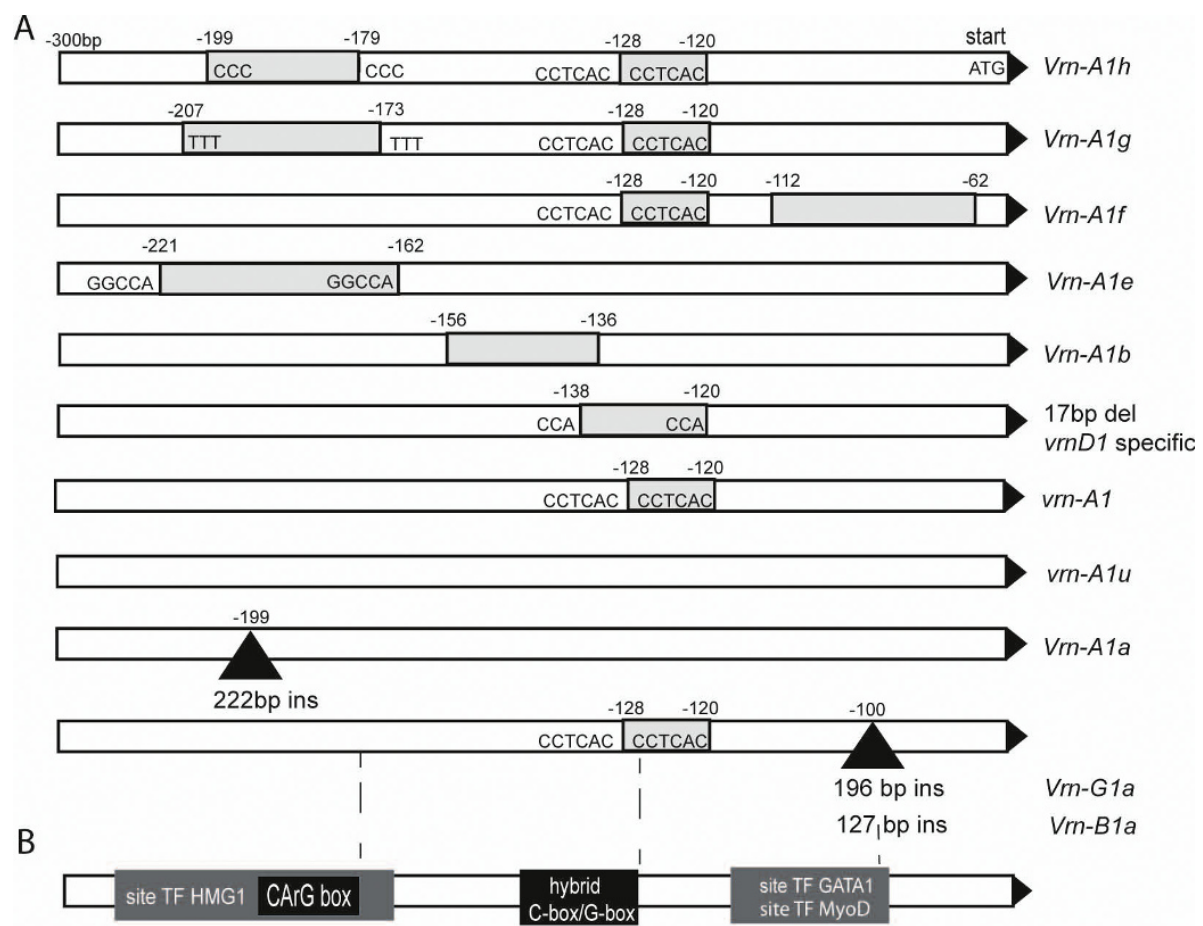

Figure 3 Indels and regulatory sites found in VRN1 promoter region. A. Schematic representation of the different VRN 1 promoter variants observed in spring wheat accessions. Places of indels are marked in bp. numbers upstream from the start codon. Grey boxes indicate deletions and black triangles - insertions. One of the direct repeats flanked deletions that remain in sequence after recombination is outside the grey box. B. The predicted transcription factors binding sites. 


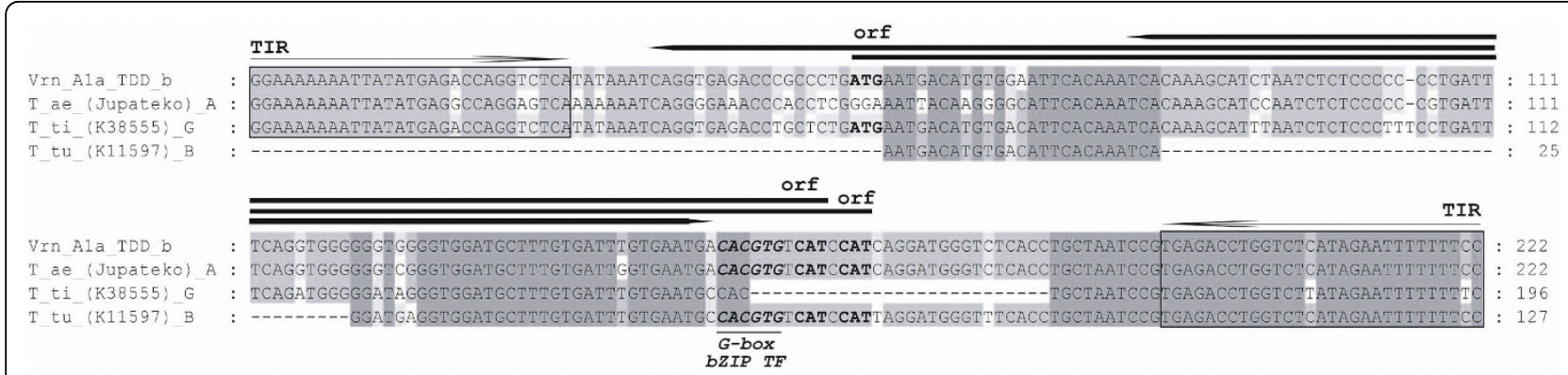

Figure 4 Alignment of foldback elements insertion observed in different VRN1 alleles. T_ae-T. aestivum, T_ti-T. timopheevii, T_tu-T. turgidum, TDD-T. aestivum (near-isogenic line Triple Dirk D).

urartu collection under Ac.N.PI428276 and later was determined as tetraploid according to karyological and molecular analyses. Four different promoter variants were found. At the same time, no positive result was obtained in PCR with $\mathrm{B} / \mathrm{G}$ genome specific primers for $V R N 1$ promoter region and developed previously for $A c c-1$ and $P g k-1$ genes [18].

Three spring cultivars of hexaploid T. aestivum also contain at least two VRN1 promoter variants in A genomes (Fig. 5). VRN1 promoter region of A genome of cv. Mironovskaya yarovaya and line nulli5B-tetra5D Chinese Spring included the recessive $v r n-A 1$ and the dominant $V r n-A 1 f$ alleles. Cultivar Jupateko had in addition the third allele differed from others by a transposon insertion.

\section{Predicted regulatory elements inside VRN1 promoter region}

In the present work, we performed the analysis of the cis-regulatory elements (recognition sites for transcription factors, TF) inside the most variable region of the VRN1 promoter. This information helps to investigate the consequences of the damages in the promoter of the main initiation factor of flowering, and possibly is related to the mechanism of growth habit changing.

Previously, a specific CArG-box common for all MADS-box protein family was found in the region where different in size deletions and transposon insertion occurred in spring diploid and polyploid wheat species. It was suggested that CArG-box could be involved in the regulation of VRN1 by interacting with other MADS-box proteins [3]. Our analysis showed that this region also included recognition site for HMG1, a high mobility globular protein, with a high probability (error type I -0.2308, error type II - 0,03882, psum -91, 074, Fig. 3B). Recently, an increased expression of wheat homolog HMG1B protein after cold exposure of crown tissue was showed [19]. The HMGB1 is thought to interact with histones and could participate in modifying chromatin structure.
Some other regulatory sites were found in the region of $20 \mathrm{bp}$ and $50 \mathrm{bp}$ deletions common for $\mathrm{Vrn}-\mathrm{A} 1 \mathrm{~b}$ and $V r n-A 1 f$ alleles, correspondingly (Fig. $3 \mathrm{~B}$ ). We also observed the recognition site (G/C hybrid box) for bZIP proteins. The VRN3 (TaFT) protein was shown to upregulate VRN1 expression via interaction with TaFDL members of bZIP transcription factor family $[6,20]$. Moreover, it appears that TaFDL2 protein can interact in vitro with ACGT elements of the promoter of the meristem identity gene VRN1, including G-box and G/C hybrid of G- and C-boxes (CACGTC). It is interesting that both transposon insertions observed in $\mathrm{B}$ and $\mathrm{G}$ genomes contain additional G-box motif (CACGT $\underline{\text { ) }}$ (Fig. 4).

Near the region of the G/C hybrid box we found the binding motifs for MyoD-like protein, a member of the bHLH family of transcription factors (error type I -1, error type II - 5,2e-05, psum -94,4257) (Fig. 3B). Members of the bHLH family in animals have been shown to regulate the determination and differentiation of a variety of cell types, including skeletal muscle, neurons, and hematopoietic cells. Recent detailed study into the physical interaction among the bHLH proteins of Arabidopsis that control stomatal development reflected that a similar mechanism functions in animal muscle and plant stomata $[21,22]$. It is known also that markers of myogenic specification such as $M y o D$ and myogenin gene, which encode transcription factors of the basic helix-loop-helix family, interact with proteins belonging to the MADS-box transcription factors [23]. It is likely that examined bHLH proteins (myoD-like) modulate cell cycle regulatory protein activity in a similar fashion in both animal and plant cells.

A binding motif was also found for GATA1 protein (error type I -0,1111, error type II -0,00451, psum -90,1055) (Fig. 3B). GATA transcription factors are a group of DNA binding proteins broadly distributed in eukaryotes. Four classes of these proteins are described in plants [24]. Some GATA transcription factors are downstream effectors of floral homeotic gene action in 


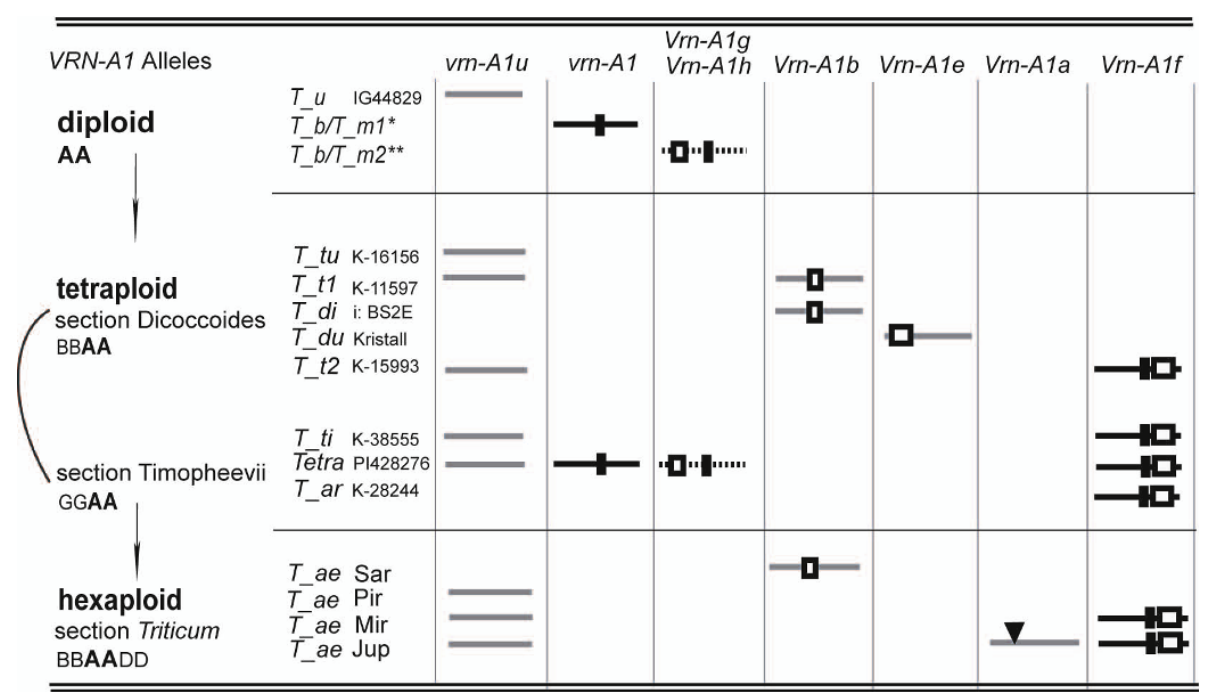

Figure 5 Variable VRN-A1 promoter copies. Boxes depict deletions (small black box -8 bp deletion), triangles - transposon insertion. T_m -T. monococcum, $T_{-} u-T$. urartu, $T_{-} b-T$. boeoticum, $T_{-} t u-T$. turgidum, $T_{-} d i-T$. dicoccum, $T_{-} d u-T$. durum, $T_{-} t-T$. turanicum, $T_{-} t i-T_{\text {. timopheevii, }}$ T_ar - T. araraticum, T_ae Sar - T. aestivum s: Saratovskaya/Nietnamskaya 5R(5A), T_ae Pir - T. aestivum cv. Pyrothrix 28, T_ae Mir - T. aestivum cv. Mironovskaya yarovaya, $T_{-} a e$ Jup - T. aestivum cv. Jupateko. $T_{-} b / T_{-} m$ 1,2 and $T_{-} t 1,2$ show two different allele's variants between accessions of indicated species. Accession number: * - T. m. winter -PI94743, spring - K-20400, Mute KT3-5, K-20970, PI306540; T. b. winter - G1777, K-25811, spring - K-14384, PI428217, IG116196. ** - T. m. spring - K-18105 (Vrn-A1g); T. b. spring - IG116198, PI427328, K-20741, IG45296, K-40118, KU8136, KU8120, KU8059 (Vrn-A1h), K-40117 (Vrn-A1g).

Arabidopsis [25]. It appears that two MADS-box gene products, APETALA3 (AP3) and PISTILLATA (PI) can directly interact with two members of GATA transcription factor family. Altogether they regulate a variety of light and nutrient responsive genes participating into the transcriptional cascades controlling the specification of floral organ identities. In particular, APETALA1 gene (homolog of VRN1 gene in wheat) is directly regulated by AP3 and PI in Arabidopsis [26].

Transcription factor binding motifs described here are found in the VRN1 promoter region where indels could induce flowering without cold treatment. This could indicate a possibility that wheat homologs of the HMG1, bZIP, bHLH and GATA1 proteins are involved in the vernalization response. Further experimental approaches are necessary to support this suggestion.

\section{Discussion}

\section{Triticum genetic material}

Notwithstanding the short evolutionary time since the domestication, some significant morphological changes were accumulated in cultivated plants. As a result of an intensive cultivation, many wheat varieties with different agronomical important characteristics were selected. However, in many cases the molecular pathway behind the appearance of a sample with an unusual character in the stable population is still unknown.

Winter growth habit is assumed to be a more ancestral character than the spring one. It is not known whether the ancient farmers found spring forms in nature or in their plots. However, they started to cultivate spring forms intensively. Among the first wheat species cultivated by people, T. monococcum and T. dicoccum, most have spring forms according to the last investigation of 284 and 563 accessions correspondingly [13]. The winter forms came back to occupy considerable areas in the middle latitudes at the beginning of the $20^{\text {th }}$ century. But in the continental middle latitude areas (countries like Kazakhstan, Russia, Ukraine, Belorussia, Canada) the field is occupied by winter forms for two vegetation seasons and by spring forms - for one season only. This is due to the agronomical aspects of spring forms - sowing in spring when winter is too cold. In these countries it is impossible to use the intermediate forms, which are used in Southern Europe and Mediterranean region, because of climate, when spring crop can not survive in winter. It appears that, when both forms are used, winter ones are often less economically beneficial. For this purpose, mutants with spring alleles of VRN1 in different genomes (A, B, D) were developed. Multiple alleles have been described within the VRN1 locus, based on their different effects on vernalization requirement and flowering time $[15,16,27,28]$. However, characterization of these alleles at the molecular level is necessary. The number of dominant $V R N$ genes in common wheat is important since it modifies spring growth habit, and allows for the development of commercial cultivars with different vegetative periods. 
Studying the unique collection of spring wild and domesticated diploid and polyploid wheats not examined before allowed us to observe a greater variability, especially in tetraploid and hexaploid species. We described three additional VRN1 promoter variants $V r n$ $A 1 f$, Vrn-A1g and Vrn-A1h. Moreover, we showed that $V R N 1$ promoter region of $\mathrm{B}$ and $\mathrm{G}$ genomes can also contain damages such as the insertion of a transposable element. The duplication of the VRN1 promoter together with the first exon was also demonstrated.

\section{Inheritance of VRN1 gene from spring wild diploids to cultivated diploids}

It is known that wild diploid wheats were the donors of A genome in polyploid wheat species. Diploid species are the most ancient in the Triticum genus so their genome (A genome) has the longest history in the genome composition of the modern wheat species. The majority of the wild wheats have a winter growth habit, suggesting that the recessive vrn-A1 allele with an intact VRN1 promoter is the ancestral character. We studied the number of wild and cultivated diploid species, and established that VRN1 promoter deletions that resulted in the elimination of repressor influence in cultivated species T. monococcum are also common for wild species $T$. boeoticum. Therefore, it is possible to conclude that spring forms originated in wild populations and later were selected by man for culture. New alleles may result from selection of independent mutations that appeared during the domestication.

It is likely that a shorter $20 \mathrm{bp}$ deletion appeared first and then increased to 34 bp deletion. Both variants were inherited by cultivated diploid forms and could be inherited also by polyploids.

Species of the genus Aegilops are closely related to wheats; they have common geographic range, and about 0.5 million years ago a first polyploid wheat appeared as a result of hybridization of wheats with goatgrasses [29]. Similar to wild diploid spring Triticum species, there are early-flowering forms among Aegilops species, which evolved in two intraspecific lineages, Middle Asian and Transcaucasian [30]. The existence of longitudinal and latitudinal clines in the onset of flowering at the species level was observed; however, mechanism controlling switch from vegetative to generative growth habit is unknown. To answer the question whether these mechanisms have common characters with that of diploid wheats we analyzed VRN1 promoter regions of several Aegilops accessions. Spring Ae. squarrosa accessions originated from the northern part of Afghanistan and Iran while in other regions only winter forms were usually found [31]. However, no indel events were found inside the investigated region. Therefore, taking into account the genealogical and ecological framework complexity of flowering time diversification in the investigated Aegilops accessions we expect the existence of another regulatory mechanism controlling flowering time in goatgrass species.

\section{Increasing genetic variability in spring tetraploids within $A$, B, and $G$ genomes}

In contrast with wild Triticum species, the majority of cultivated polyploid wheat species have spring growth habit [13]. Spring forms are due to at least one dominant mutation in VRN1 gene that could be inherited or appeared independently during domestication or historical selection process.

Four different variants of VRN1 promoter in A genomes of diploid species were observed (Fig. 5). The main difference between sequences is the presence or absence of a specific 8 bp deletion that was not observed only in one spring accession of T. urartu and inherited by A genome of many polyploids.

In comparison with diploid species three other new $V R N 1$ promoter variants due to deletions appeared in tetraploids. One of them represents $\mathrm{Vrn}$-Ale allele and contains 54 bp deletion in place where specific 20 and 34 bp deletions occurred in diploids. Possibly there was a deletion expansion in tetraploids but independent appearance is also likely due to the existence of flanking direct repeats, which may be the reason of nonhomologous recombination (Fig. 3). There are many different repeat regions inside $V R N 1$ promoter and most of the deletions flanked by short direct repeats (Fig. 3). It was shown that unequal recombination by such repeats can play the main role in the origin of novel alleles in VRN1 gene [32]. The Vrn-A1e allele could have originated from the allele containing $8 \mathrm{bp}$ insertion and observed only in one wild diploid species T. urartu.

Another $V r n-A 1 b$ allele found in tetraploids contains a $20 \mathrm{bp}$ deletion (Fig. 3). Its origin is also related to $T$. urartu VRN1 promoter containing 8 bp insertion (Fig. 5). The described deletion most likely happened in species of Dicoccoides section. This allele is not found in wheat species from Monococcon Dum. and Timopheevii sections. At the same time, Vrn-Alf allele likely occurred in Timopheevii section within species with G genomes (Fig. 5). Moreover, its origin is related to diploid VRN1 promoter containing 8 bp deletion. We found this allele also in T. turanicum (section Diccocoides); this, however, is likely a case of hybridization event that may occur between tetraploid species from different wheat sections.

The VRN1 promoter variant found in T. dicoccum accession (near-isogenic line BS1E) had all common characters of $V r n-A 1 a$ allele as well as the transposon insertion (Fig. 3). Taking into consideration the origin of BS1E line, as the near-isogenic line of cv. Black Winter Emmer whose vrn- 
$A 1$ allele was replaced with $V r n-A 1 a$ of hexaploid wheat Triple Dirk (TDD) by backcrossing, this proves its derivation from T. aestivum near-isogenic line TDD.

We found and described also two different alleles in B and $\mathrm{G}$ genomes of tetraploid species that contain a transposon insertion (Vrn-G1a, Vrn-B1a, Fig. 4). The indel events in these genomes were observed for the first time, and both species contained also VRN1 promoter damages in A genomes. Investigated hexaploid accessions of section Triticum inherited all alleles from tetraploid species except one with transposon insertion that most likely happened at this ploidy level (Fig. 5).

\section{Evidence of the VRN1 promoter duplication}

In the present work, two and more VRN1 promoter copies were detected and distinguished by the presence of indel events within A genome of several spring polyploid species. There are three possible explanations of these results: (1) nonspecific duplication of different genomes, (2) heterozygous plant material with two different chromatids in one genome, (3) duplication of the investigated region. The first possibility was tested by the presence of the nucleotide substitutions and indel events specific to different genomes. For more reliable results the phylogenetic tree was constructed that demonstrated relatedness of each clone to certain genomes. Results showed an absence of nonspecificity and supported attributes of each clone to genome which amplification product was cloned. The genetic experiment and clearance of each examined lines exclude the second possible case. All accessions with two and more $V R N 1$ promoter variants contained one intact promoter that was observed in winter plants. However no splitting was detected in five generations of each line.

The most likely explanation is the duplication of the investigated region that occurred in polyploid species. Previously it was supposed the duplication of the promoter region with the first exon in Vrn-A1a allele [10]. In most cases we found two copies of the promoter that differed by the presence of deletions. Exceptions were accessions of T. dicoccoides (PI428276) and cv. Jupateko of common wheat (Fig. 5).

In most polyploid VRN1 promoter variants, an ancestral form is an intact winter allele found only in $T$. urartu accession. The second VRN1 promoter sequences that was found in diploids and contained $8 \mathrm{bp}$ del was inherited by some tetraploids of section Timopheevii. In the genome of ancestor species of this group additional 50 bp deletion occurred.

It is most likely that duplication of the promoter region occurred before deletion formation and transposon insertion. Moreover, deletions occurred in polyploid species independently from diploid species. Therefore, spring forms, which resulted from indels, were not inherited from spring diploid species. The obtained data demonstrated that quite complicated molecular alterations occurred in the studied region of spring polyploid species. Two main underlying causes of such dynamic evolutionary changes seem to be polyploidy and intensive breeding of agronomic characters.

\section{Conclusions}

In the present study we investigated variability in the promoter region of vernalization gene $V R N 1$ in spring wheat accessions. A greater variability in the VRN1 promoter region of polyploid species in comparison with diploid ones was observed. In diploid species, damages of VRN1 promoter leading to spring growth habit were inherited by cultivated forms from the wild. A complicated evolutionary process including duplication of VRN1 promoter was found in A genome of polyploids. Different indel events likely occurred in spring polyploid species independently from spring diploid species. Specific transposon insertions found in A genome as well as in B and G genomes of spring tetraploid species pointed to active transposition in polyploid genome. Some transcription element binding sites were observed in silico in the regions of indel events.

\section{Methods}

\section{Plant materials}

The wheat accessions, goatgrasses and rye were received from the different genebanks of Russia, Japan, the USA and ICARDA (Syria, Table 3). In the present work all used accessions were grown, and their generic definitions and growth habit (spring vs. winter) were determined. The botanical names of wheat species and their genomic formulas are given according to Goncharov (2002, 2009) [33,34]. VRN1 promoter sequences of 27 accessions belonging to four diploid wheat species (T. urartu, T. boeoticum, T. monococcum and T. sinskajae), seven goatgrass accessions belonging to Aegilops speltoides and Ae. squarrosa (syn. Ae. tauschii) together with 17 accessions of seven polyploid species belonging to three known sections (Dicoccoides, Triticum, Timopheevii) were studied. Their accession numbers, phenotypes and genotypes are given in Table 3.

\section{Greenhouse and genetic experiments}

In the first experiment, the growth habits of di-, tetraand hexaploid wheat species were investigated. Growth habit was analysed by spring sowing avoiding even partial vernalization. Three months after sowing in the field, when all the spring standard varieties had already headed, experimental materials were classified as spring (ear emergence) or winter (no visible ear formation).

To identify the VRN genotype and the number of dominant genes in diploid and tetraploid wheat segregations in the $F_{2}$ hybrids were scored according to 
Goncharov (2004) [35], i.e. three months after sowing, when all the standard spring cultivars had already headed, and when it was possible to classify the hybrid plants as spring (ear emerged) or as winter (no visible ear formation). Emasculation of mother plant spikes was performed for producing $F_{1}$ generation plants and they were pollinated by flowering father plant spikes using twirl-method. The segregation ratio for each cross was determined and compared with the expected segregation ratio using the Pierson chi-square test. Ten spring diploid accessions (T. boeoticum -IG116196, IG116198, K-20471, IG45296; T. monococcum - Mute KT3-5, T. sinskajae - K-48993, Ae. squarossa, - K-992, K-608, K865, KU2009) and three tetraploid species (T. turgidum - K-16156, T. durum cv. Kristall, T. turanicum - K15993) were studied in genetic experiments. Since allelism test was impossible between diploid species and polyploid species, only the number of dominant genes was determined for diploids.

In the second experiment we produced the near-isogenic lines based on a Black Winter Emmer T. dicoccum accession with dominant $\mathrm{Vrn}$ genes introgressed from near-isogenic lines of common wheat cv 'Triple Dirk' to analyse the growth habit and VRN genotype in tetraploid wheats [36]. They allowed to carry out methodical experiments and, later, to study allelism of dominant genes of common and tetraploid wheats.

In total, among 43 spring accessions for 10 of them the number of genes responsible for spring $v s$. winter growth habit and Vrn genotype for three tetraploid species were estimated in the present study, for 13 spring wheat and goatgrasses $\mathrm{Vrn}$ genotype and a number of dominant genes were known from previous works.

It was shown previously that all winter wheat had no deletions in the VRN1 promoter region [3,10]. The VRN1 promoter region of winter mPI306547 accession is available from Genbank (DQ146423). VRN1 promoter sequences of two other winter accessions ( $T$. urartu - K33869 , T. boeoticum - K-25811) from our genetic experiments together with some another were investigated in the molecular part of the study for their comparison.

\section{Total DNA isolation, primer design, PCR amplification, cloning, DNA sequencing}

The total DNA was isolated from 50-170 mg of acrospires using a standard CTAB method [37]. DNA were checked by electrophoresis in a $1 \%$ agarose gel containing ethidium bromide $(0.5 \mathrm{mg} / \mathrm{mL})$ in $1 \mathrm{xTAE}$. Primer pairs used in the study are presented in the Table 4.

Selection of the appropriate oligonucleotide sequences was provided with the help of Vector NTI Suite 9.0 program [38]. All PCR reactions were performed in a volume of $20 \mu \mathrm{l}$ containing $65 \mathrm{mM}$ Tris- $\mathrm{HCl}(\mathrm{pH} \mathrm{8.9)}, 16 \mathrm{mM}$ $\left(\mathrm{NH}_{4}\right)_{2} \mathrm{SO}_{4}, 1.5 \mathrm{mM} \mathrm{MgCl} 2,10 \% \mathrm{DMSO}, 200 \mu \mathrm{M}$ of each dNTP, $0.5 \mu \mathrm{M}$ of each primer, 20-50 ng genomic DNA template, and $1 \mathrm{U}$ of Taq DNA polymerase. The touch-down PCR program had an initial strand separation step at $94^{\circ} \mathrm{C}$ for $3 \mathrm{~min}$ followed by 15 cycles of denaturation at $94^{\circ} \mathrm{C}$ for $30 \mathrm{~s}$, annealing at $65^{\circ} \mathrm{C}$ with delta $\mathrm{RT}-1^{\circ} \mathrm{C}$ in each cycle for $30 \mathrm{~s}$ and elongation at $72^{\circ} \mathrm{C}$ for $40 \mathrm{~s}$; after that, similar 25 cycles with annealing temperature $50^{\circ} \mathrm{C}$. The PCR products were analyzed in agarose gel electrophoresis, extracted from gel with a Qiaquick Gel Extraction Kit (Qiagene; according to manufacturer's protocol) and either sequenced directly or cloned into pCR 4-TOPO TA vectors (Invitrogen) and then sequenced using M13 primers. $200 \mathrm{ng}$ of the PCR product was used in a $10 \mu \mathrm{l}$ cycle sequencing reaction with the ABI BigDye Terminator Kit on an ABI 377 Genetic Analyser (Applied Biosystems, http://www.appliedbiosystems.com). The obtained sequences were deposited to GenBank (Table 3).

\section{Allelic variation at the VRN1 promoter region in diploid and polyploid wheats}

In the present work, VRN1 promoter sequences of wild and cultural diploid and polyploid wheats with different alleles were investigated to elucidate variability and possible evolution of promoter damages leading to growth habit change. PCR screening of diploid wheat was provided with primer pairs AP1_ProDel_F1/AP1_ProDel_R1 and AP1_2F/ AP1_2R (Table 4). The expected PCR products were about $152 \mathrm{bp}$ and $200 \mathrm{bp}$ long. Using previously developed primer pairs specific for amplification of different genomes we analyzed A, B, G and D genomes of 17 tetra- and hexaploid wheats from three different sections (Table 3). Some of the PCR products were sequenced directly. Others products were cloned into a plasmid vector, and then three to five individual clones were sequenced for each sample. The length of the obtained fragments varied from about $700 \mathrm{bp}$ for A genome to about $1200 \mathrm{bp}$ for B genome sequences. Most of the obtained sequences contained genome-specific substitutions and indels. All sequences were deposited in the GenBank: diploids - GQ451714-GQ451749; polyploids - GQ451750-GQ451822, GQ482969-75. Spring accessions were compared with winter ones; their important differences are described below.

\section{Variability of different clones inside $A$ genome}

For some polyploid accessions, PCR products of the $V R N 1$ promoter region were cloned into a plasmid vector, and individual clones were sequenced. In most cases, cloning was performed for accessions where unreadable chromatograms were obtained after direct sequencing. All PCR products of studied diploids were successfully directly sequenced. Therefore, the problem could occur due to the polyploidy or the presence of different promoter variants in one genome of polyploid species [10]. It turned out that variability between different clones was sometimes quite high (Table 3). Based on the specific 
nucleotide substitutions, it was possible to distinguish between different genomes of polyploid species.

\section{Sequences and phylogenetic analysis}

The nucleotide sequences were aligned using ClustalW [39] and improved by MUSCLE algorithm in UGene software http://ugene.unipro.ru edited using the GenDoc Version 2.6.002 [40]. The phylogenetic analysis was performed in the MEGA 4.0 program based on all obtained sequences of the different clones from polyploid wheat (GQ451750-93, 95-99; GQ451800-19). Sequences of the different genomes of winter $T$. aestivum TDC line (AY747600, AY747604, AY747606) were used as a control, and vrn-H1 sequence of Hordeum vulgare cv. Strider, as an outgroup (AY750993) [41]. Statistical support for the tree was evaluated by bootstrapping [42].

\section{Regulatory sites analysis}

The UniPro Ugene software was used for searching and analysis of repeat and regulatory elements. The integrated plugin Sitecon was used for TF site recognition. This tool was developed for detecting conservative conformational and physicochemical properties in transcription factor binding site alignments and for site recognition [43].

\section{Additional material}

\section{Additional file 1: Alignment of VRN1_D genome sequences. $T$.}

aestivum TDC vrn-A1, B1, D1 were obtained from GenBank: AY747600,

AY747604, AY747606. D1, D2, D3... - depict different clones of one sample. MIR 808 -Mironovskaya 808 (winter), MIR_S - Mironovskaya yarovaya (spring), MIR_W - Mironovskaya yubileinaya (winter), N5BT5D nulli5B-tetra5D, PIR28 - Pyrothrix 28, SN - s: Saratovskaya/Vietnamskaya $5 R(5 A)$.

Additional file 2: Alignment of VRN1_B, G genome sequences. T. aestivum TDC vrn-A1, B1, D1 were obtained from GenBank: AY747600, AY747604, AY747606. B1, B2, B3...- depict different clones of one sample. MIR 808 -Mironovskaya 808 (winter), MIR_W - Mironovskaya yubileinaya (winter), SARNIE - s: Saratovskaya/Nietnamskaya 5R(5A).

Additional file 3: Maximum likelihood phylogenetic analysis of the obtained VRN1 clones. T. aestivum TDC Vrn-A1, BI, D1 were obtained from GenBank: AY747600, AY747604, AY747606. vrnH1 sequence of Hordeum vulgare (Strider) was used as an outgroup (Genbank: AY750993). A1, A2, A3... - depict different clones of one sample. T_d - T. dicoccum, T_tu - T. turanicum, T_aes - T. aestivum, Tetra - tetraploid line, T_ti - T. timopheevii, T_t - T. turgidum, T_a - T. araraticum. MIR 808 -Mironovskaya 808 (winter), MIR_S - Mironovskaya yarovaya (spring), MIR_W -

Mironovskaya yubileinaya (winter), N5BT5D - nulli5B-tetra5D, PYR -

Pyrothrix 28, SN - s: Saratovskaya/Nietnamskaya 5R(5A), Jup - Jupateko,

Os - Osijek. Sequences of tetraploid PI428276 - Genbank: GQ482969-75

\section{Acknowledgements}

We are grateful to Dr. H. Bockelman (the National Small Grains Collection, Aberdeen, USA), Dr. T. Kawahara (Graduate School of Agriculture of Kyoto Univ., Kyoto, Japan), Drs. R.A. Udachin, O.P. Mitrofanova and N.A. Anfilova (N. I. Vavilov All-Russian Institute of Plant Industry, St-Petersburg, Russia), Dr. J. Valkoun (ICARDA, Aleppo, Syria) for supplying seeds of wheat species. We appreciate greatly the help of Dr. Victor Fet for written language proofreading. The partial financial support of this investigation was provided by the Russian Foundation for Basic Research (Grant №09-04-01382-a).

\section{Author details}

'Laboratory of Molecular-Genetic Systems, Institute of Cytology and Genetics, Novosibirsk 90, Russian Federation. ${ }^{2}$ Laboratory of Wheat Genetics, Institute of Cytology and Genetics, Novosibirsk 90, Russian Federation.

\section{Authors' contributions}

KG designed the study, carried out the molecular and bioinformatics experiment, drafted the manuscript. EYK and NPG carried out greenhouse and genetic analysis. NPG helped draft the manuscript. AB conceived the study, helped with an interpretation the results and critically revised the manuscript. All authors read and approved the final manuscript.

Received: 31 August 2009 Accepted: 11 August 2010

Published: 11 August 2010

\section{References}

1. Flood RG, Halloran GM: Genetics and physiology of vernalization response in wheat. Advance Agronomy 1986, 39:87-125.

2. Danyluk J, Kane NA, Breton G, Limin AE, Fowler DB, Sarhan F: TaVRT-1, a putative transcription factor associated with vegetative to reproductive transition in cereals. Plant Physiol 2003, 132:1849-1860.

3. Yan L, Loukoianov A, Tranquilli G, Helguera M, Fahima T, Dubcovsky J: Positional cloning of the wheat vernalization gene VRN1. Proc Natl Acad Sci USA 2003, 100:6263-6268.

4. Yan L, Loukoianov A, Blechl A, Tranquilli G, Ramakrishna W, SanMiguel P, et al: The wheat VRN2 gene is a flowering repressor down-regulated by vernalization. Science 2004, 303:1640-1644.

5. Yan L, Fu D, Li C, Blechl A, Tranquilli G, Bonafede M, et al: The wheat and barley vernalization gene VRN3 is an orthologue of FT. Proc Natl Acad Sci USA 2006, 103:19581-19586.

6. Li C, Dubcovsky J: Wheat FT protein regulates VRN1 transcription through interactions with FDL2. Plant J 2008, 55:543-554.

7. Trevaskis B, Hemming MN, Dennis ES, Peacock WJ: The molecular basis of vernalization-induced flowering in cereals. Trends Plant Sci 2007, 12:352-357.

8. Bonnin I, Rousset M, Madur D, Sourdille P, Dupuits C, Brunel D, et al: FT genome $A$ and $D$ polymorphisms are associated with the variation of earliness components in hexaploid wheat. Theor Appl Genet 2008, 116:383-394.

9. Dubcovsky J, Loukoianov A, Fu D, Valarik M, Sanchez A, Yan L: Effect of photoperiod on the regulation of wheat vernalization genes VRN1 and VRN2. Plant Mol Biol 2006, 60:469-480.

10. Yan L, Helguera M, Kato K, Fukuyama S, Sherman J, Dubcovsky J: Allelic variation at the VRN-1 promoter region in polyploid wheat. Theor Appl Genet 2004, 109:1677-1686.

11. Fu D, Szucs P, Yan L, Helguera M, Skinner JS, von ZJ, et al: Large deletions within the first intron in VRN-1 are associated with spring growth habit in barley and wheat. Mol Genet Genomics 2005, 273:54-65.

12. Pidal B, Yan L, Fu D, Zhang F, Tranquilli G, Dubcovsky J: The CArG-box located upstream from the transcriptional start of wheat vernalization gene VRN1 is not necessary for the vernalization response. J Hered 2009, 100:355-364.

13. Goncharov NP: Genetic resources of wheat related species:The Vrn genes controlling growth habit (spring vs. winter). Euphytica 1998, 100:371-376.

14. Iwaki K, Haruna S, Niwa T, Kato K: Adaptation and ecological differentiation in wheat with special reference to geographical variation of growth habit and Vrn genotype. Plant Breeding 2001, 120:107-114.

15. Koval SF, Goncharov NP: Multiple allelism at the Vrn1 locus of common wheat. Acta Agronomica Hungarica 1998, 46:113-119.

16. Rhone B, Remoue C, Galic N, Goldringer I, Bonnin I: Insight into the genetic bases of climatic adaptation in experimentally evolving wheat populations. Molecular Ecology 2008, 17:930-947.

17. Kilian B, Ozkan H, Deusch O, Effgen S, Brandolini A, Kohl J, et al: Independent wheat $\mathrm{B}$ and $\mathrm{G}$ genome origins in outcrossing Aegilops progenitor haplotypes. Mol Biol Evol 2007, 24:217-227.

18. Goncharov NP, Golovnina KA, Kilian B, Glushkov AG, Shumnyi VK: Evolutionary history of wheats - the main cereal of mankind. Biosphere Origin and Evolution SpringerDobretsov N 2008, 407-419. 
19. Christov NK, Imai R, Blume Y: Differential expression of two winter wheat alpha-tubulin genes during cold acclimation. Cell Biol Int 2008, 32:574-578.

20. Fu D, Dunbar M, Dubcovsky J: Wheat VIN3-like PHD finger genes are upregulated by vernalization. Mol Genet Genomics 2007, 277:301-313.

21. Kanaoka MM, Pillitteri LJ, Fujii H, Yoshida Y, Bogenschutz NL, Takabayashi J, et al: SCREAM/ICE1 and SCREAM2 specify three cell-state transitional steps leading to arabidopsis stomatal differentiation. Plant Cell 2008, 20:1775-1785.

22. Serna L: Emerging parallels between stomatal and muscle cell lineages. Plant Physiol 2009, 149:1625-1631.

23. Brand-Saberi B: Genetic and epigenetic control of skeletal muscle development. Ann Anat 2005, 187:199-207.

24. Reyes JC, Muro-Pastor MI, Florencio FJ: The GATA family of transcription factors in Arabidopsis and rice. Plant Physiol 2004, 134:1718-1732.

25. Mara CD, Irish VF: Two GATA transcription factors are downstream effectors of floral homeotic gene action in Arabidopsis. Plant Physiol 2008, 147:707-718.

26. Sundstrom JF, Nakayama N, Glimelius K, Irish VF: Direct regulation of the floral homeotic APETALA1 gene by APETALA3 and PISTILLATA in Arabidopsis. Plant J 2006, 46:593-600

27. Roberts DWA, McDonald MD: Evidence for the multiplicity of alleles at Vrn1, the winter-spring habit locus in common wheat. Canadian Journal of Genetics and Cytology 1984, 26:191-193.

28. Tsunewaki $K$, Jenkins BC: Monosomic and conventional gene analysis in common wheat. II. Growth habit and awnedness. Japan Journal of Genetics 1961, 46:428-443.

29. Gill BS, Appels R, Botha-Oberholster AM, Buell CR, Bennetzen JL, Chalhoub $B$, et al: $A$ workshop report on wheat genome sequencing: International Genome Research on Wheat Consortium. Genetics 2004, 168:1087-1096.

30. Matsuoka $Y$, Takumi S, Kawahara T: Flowering time diversification and dispersal in central Eurasian wild wheat Aegilops tauschii Coss.: genealogical and ecological framework. PLOS ONE 2008, 3:e3138.

31. Goncharov NP, Chikida NN: Genetics of growth habit in Aegilops squarrosa. Genetika 1995, 31:396-399.

32. Cockram J, Mackay IJ, O'Sullivan DM: The role of double-stranded break repair in the creation of phenotypic diversity at cereal VRN1 loci. Genetics 2007, 177:2535-2539.

33. Goncharov NP: Comparative genetics of wheats and their related species Novosibirsk: Siberian University Press 2002

34. Goncharov NP, Golovnina KA, Kondratenko EY: Taxonomy and molecular phylogeny of natural and artificial wheat species. Breeding Science 2009, 59:492-498.

35. Goncharov NP: Response to vernalization in wheat: its quantitative or qualitative nature. Cereal Research Communication 2004, 32:323-330.

36. Goncharov NP: Genetics of growth habit (spring vs. winter) in tetraploid wheats: production and analysis of near-isogenic lines. Hereditas 1999, 130:125-130

37. Rogers $\mathrm{SO}$, Bendich AJ: Extraction of DNA from milligram amounts of fresh, herbarium and mummified plant tissues. Plant Mol Biol 1985, 5:69-76.

38. Lu G, Moriyama EN: Vector NTI, a balanced all-in-one sequence analysis suite. Brief Bioinform 2004, 5:378-388.

39. Larkin MA, Blackshields G, Brown NP, Chenna R, McGettigan PA, McWilliam $H$, et al: Clustal W and Clustal X version 2.0. Bioinformatics 2007, 23:2947-2948.

40. Nicholas KB, Nicholas HB Jr, Deerfield DW: GeneDoc: Analysis and Visualization of Genetic Variation. EMBNEW NEWS 1997, 4.

41. Tamura K, Dudley J, Nei M, Kumar S: MEGA4: Molecular Evolutionary Genetics Analysis (MEGA) software version 4.0. Mol Biol Evol 2007, 24:1596-1599.

42. Felsenstein J: Confidence limits on phylogenies: an approach using the bootstrap. Evolution 1985, 39:783-791.

43. Oshchepkov DY, Vityaev EE, Grigorovich DA, Ignatieva EV, Khlebodarova TM: SITECON: a tool for detecting conservative conformational and physicochemical properties in transcription factor binding site alignments and for site recognition. Nucleic Acids Res 2004, 32: W208-W212.

44. Lebedeva TV, Rigin BV: Inheritance of some morphological characters, growth habit and resistance to powdery mildew in cultivated diploid Triticum monococcum L. Genetika 1994, 30:1599-1604.
45. Goncharov NP, Kondratenko El, Bannikova SV, Konovalov AA, Golovnina KA: Comparative genetic analysis of diploid naked wheat Triticum sinskajae and the progenitor T. monococcum accession. Russian Journal of Genetics 2007, 43:248-256.

46. Sears ER: The aneuploids of common wheat. Mo Agr Exp Station Res Bull 1954, 572:1-59.

47. Goncharov NP, Shitova IP: The inheritance of growth habit in old local varieties and landraces of hexaploid wheat. Russian Journal of Genetics 1999, 35:386-392.

48. Stelmakh AF: Growth habit in common wheat (Triticum aestivum L. EM. Thell.). Euphytica 1987, 36:513-519.

doi:10.1186/1471-2229-10-168

Cite this article as: Golovnina et al:: Molecular characterization of vernalization loci VRN1 in wild and cultivated wheats. BMC Plant Biology 2010 10:168.

\section{Submit your next manuscript to BioMed Central and take full advantage of:}

- Convenient online submission

- Thorough peer review

- No space constraints or color figure charges

- Immediate publication on acceptance

- Inclusion in PubMed, CAS, Scopus and Google Scholar

- Research which is freely available for redistribution

Submit your manuscript at www.biomedcentral.com/submit
C Biomed Central 